\title{
Valor do Produto de Moda por Agentes Artificiais
}

\section{The Value of Fashion Product by Artificial Agents}

\author{
Gabriela Kuhnen \\ Doutoranda no Programa de Pós Graduação em Design pela Univeresidade Federal de Santa Catarina (UFSC) - \\ gabkuhnen@gmail.com- orcid.org/ 0000-0003-0307-2360 \\ Richard Perassi Luiz de Sousa \\ Doutor em Comunicação e Semiótica pela Pontifícia Universidade Católica de São Paulo (PUC/SP) - \\ richard.perassi@uol.com.br-orcid.org/ 0000-0003-0696-4110 \\ Gilson Braviano \\ Doutor em Matemática Aplicada pela Université Joseph Fourier (UGA) - \\ gilson@cce.ufsc.br-orcid.org/ 0000-0002-7967-2015
}

\begin{abstract}
Resumo
O avanço das tecnologias tem possibilitado grandes evoluções em relação ao desenvolvimento de máquinas inteligentes. Para tanto, sua programação e lógica pode ser entendida por meio dos processos semióticos que acontecem nos seres humanos. Através de interpretações de signos, as máquinas organizam informações e tomam decisões, possuindo a capacidade de aprender. Na moda, os sistemas de escolhas são complexos, pois envolvem tanto fatores materiais como intangíveis. Esse sistema de valor se estabelece em qualquer momento da cadeia produtiva e dependem especificamente dos pesos que os usuários dão para cada fator que pode variar de acordo com seu estilo de vida, cultura ou crenças. $O$ objetivo deste artigo foi realizar uma análise crítica e reflexiva em que se discute o valor do produto de moda na vida dos usuários a ponto de se tornarem passíveis de serem escolhidos por um agente externo e artificial. Acredita-se que considerando todos os níveis de circunstâncias, condições e fatores de uso a quantidade de variáveis na tomada de decisão tende ao infinito, fazendo assim com que, até o momento, seja improvável que os agentes artificiais possam gerar valor para o produto de moda da mesma forma como os seres humanos.
\end{abstract}

Palavras-chave: Moda; Inteligência artificial; Aprendizado do computador; Vestuário; Semiótica.

\section{Abstract}

The advancement of technologies has enabled major evolutions in relation to the development of intelligent machines. To this end, its programming and logic can be understood through the semiotic processes that happen in humans. Through interpretations of signs, machines organize information and make decisions, possessing the ability to learn. In fashion, choice systems are complex because they involve both material and intangible factors. This value system is established at any time in the supply chain and depends specifically on the weights users give for each factor that may vary according to their lifestyle, culture or beliefs. The aim of this paper was to conduct a critical and reflective analysis that discusses the value of the fashion product in users' lives to the point that they can be chosen by an external and artificial agent. It is believed that considering all levels of circumstances, conditions and factors of use the number of variables in decision making tends to infinity, so it is unlikely that artificial agents can generate value for fashion products in the same way as humans.

Keywords: Fashion; Artificial intelligence; Machine learning; Clothing and dress ; Semiotics.

Recebido em: 05/02/2020

Aceito em: 10/10/2021 


\section{INTRODUÇÃO}

As novas máquinas inteligentes e autônomas a cada dia ganham mais espaços nos lares e nas interações com os seres humanos. Na percepção do usuário elas parecem entender exatamente como agimos e podem tomar decisões avaliando diferentes situações. Este sistema complexo de tomada de decisão é baseado em inteligência artificial e deve ser confiável, seguro e eficiente para garantir o objetivo de ter sido criado: melhorar a vida dos usuários.

Inteligência artificial (IA) está sendo usada aqui como um termo que se refere a softwares que envolvam atividades que incluam aprendizado, planejamento, resolução de problemas e tomada de decisão. Esta tecnologia simula a cognição humana e tem o intuito de auxiliar as pessoas na realização de tarefas. Quando recebe dados, a inteligência artificial promove previsões precisas e possui uma capacidade de processamento muito mais rápida que um cérebro humano.

Além disso, sistemas como esses podem ser utilizados para resolver problemas complexos através das redes neurais. Na área do design, a IA está sendo aplicada nos processos de criação de produtos, como por exemplo em softwares generativos que produzem centenas de opções a partir de critérios inseridos pelos designers. Esses critérios incluem características, limitações e outros requisitos como custos dos materiais, etc. A partir das escolhas do designer, a IA tende a produzir outras variações cada vez mais adequadas para cada situação. No varejo, a IA é muito utilizada para interpretar dados de consumo, recomendando produtos e serviços para cada consumidor. Muitos aplicativos têm sido construídos com objetivo de melhorar a qualidade de vida e auxiliar as pessoas nas mais diversas atividades. (VIANNA et al., 2019).

Para habilitar esse tipo de máquina, os designers ou engenheiros precisam espelhar-se em processos cognitivos humanos e buscam prever todas as variáveis para programar respostas adequadas ao sistema (NORMAN, 2010). Para tanto, buscou-se neste artigo, uma reflexão por meio da semiótica com intuito de questionar o quanto um aplicativo de gerenciamento de estilos de roupas pode contemplar um sistema complexo de decisões que realmente atenda as necessidades dos usuários.

Essas máquinas semióticas que traduzem e interpretam signos, além de serem sistemas mediadores não biológicos que possuem como principal característica a autonomia na realização de processos no qual reúnem e reorganizam informações, criam conhecimento pela percepção de usuários humanos. No entanto, será possível esses aplicativos criarem conhecimentos com base em decisões emocionais? Não se pretende responder esta pergunta de forma concreta, mas por meio da investigação de conceitos da semiótica e de teorias de economia da moda, fazer uma reflexão em que se discute o valor do produto de moda na vida dos usuários a ponto de se tornarem passíveis de serem escolhidos por um agente externo e artificial.

\section{RACIOCÍNIO DE MÁQUINA}


A tomada de decisões e a cognição relacionada a resolução de certas tarefas ou problemas é um processo que envolve muitos aspectos. Nos seres humanos, isso ocorre através de reconhecimento de padrões. Para tanto, utiliza-se conhecimento adquirido durante toda a sua experiência de vida. Nas máquinas, os problemas são solucionados por meio de um algoritmo, que, especifica a forma e as regras de decisão para resolvê-lo.

Algumas tarefas são muito complexas e lidam com uma quantidade de dados tão grande que se torna praticamente impossível serem solucionadas por seres humanos. Já nas máquinas, a utilização de regras lógicas e sua capacidade de processamento possibilitam a resolução de problemas cada vez mais complexos. Quando as máquinas conseguem formular uma hipótese ou tomar uma decisão através de experiências passadas, chama-se de aprendizado de máquina (AM). Essa é uma das características fundamentais para o comportamento inteligente. (FACELI et al., 2011).

Sendo assim, a inteligência artificial refere-se a softwares que incluem o aprendizado, o planejamento e a resolução de problemas. Para tanto o AM se dá através de um mecanismo chamado de indução, que a partir de exemplos específicos, a máquina consegue inferir conclusões genéricas (FACELI et al., 2011). Esse tipo de comportamento é baseado no raciocínio humano e na forma como se processam os signos.

Os signos segundo Peirce (Apud NÖTH, 2001), são fenômenos materiais ou mentais que ser referem a um fenômeno anterior chamado de objeto do signo. Este, por consequência, resulta em outro signo por meio do interpretante que relaciona o signo primeiro com o seu objeto. A semiose é o nome dado a este processo, que em humanos acontece de forma dinâmica e contínua. Compreende então, esses três domínios: o signo, seu objeto e seu interpretante.

Apesar de a capacidade de raciocínio estar presente em muitas máquinas como em diferentes softwares e até mesmo máquinas mais simples como calculadoras, a capacidade de controle é um dos aspectos que distingue organismos biológicos. A autopoiesis é a autonomia de sistemas baseada no auto controle, típica de sistemas vivos. Diferentemente de sistemas alopoiéticos, no qual o controle é definido por algo externo. (NÖTH, 2001).

No entanto, sistemas não vivos podem ser autômatos e com níveis de realização de tarefas por si próprios. Porém, ainda sem capacidade de se auto referenciar ou ser autoconscientes. Essas máquinas, por meio desses processos, reorganizam a informação e para os usuários criam a percepção de produzir conhecimento. (SOUSA, 2019).

\section{AS MÁQUINA DE CHARLES MORRIS}

Na teoria de Charles Morris (1994), os sistemas inteligentes têm a capacidade de interagir com o meio ambiente através da recepção de signos por meio de entradas e de devolução de informação processada por meio das saídas. Neste caminho o signo percorre uma trajetória no tempo. No entanto, para que o signo seja reconhecido é necessário um módulo perceptivo. Este 
módulo deve estar ligado ao condutor de entrada e para perceber este signo é necessária uma memória no tempo atrelado a este vetor. Na sequência, o signo será interpretado pelo interpretante que é o próprio sistema, para tanto, é necessário um contexto histórico que atuará por meio de uma memória temporal atrelada ao interpretante.

Nesta trajetória do signo para ser reconhecido e atribuído um valor ou significado, comparações são feitas entre a memória perceptiva do signo e a memória armazenada no interpretante. Neste estágio existem três dimensões em que o sistema atua: designativa, apraisiva e prescritiva. (GOMIDE; GUDWIN, 1996).

A dimensão designativa baseia-se nas relações entre o signo e sua comparação com o objeto. Está relacionada com o significado e codificação do signo.

A dimensão apraisiva está relacionada as sensações e o signo é reconhecido como adequado ou não, bom ou ruim.

Segundo Gomide e Gudwin (1996), a dimensão prescritiva está ligada a decisões ou ações que serão tomadas após a aceitação do signo e tem uma relação direta com a saída do sistema. As dimensões podem ter influências uma sobre as outras no momento do processamento do signo. Essas dimensões nem sempre atuam de forma linear como descrito aqui, mas podem sofrer alterações aleatórias em suas decisões, dependendo dos impulsos gerados por cada dimensão. Os impulsos da dimensão apraisiva e prescritiva ainda podem ser subdivididos em micro e macrosistêmico. Um esquema desse processo pode ser visualizado na figura 1.

Nem todos os signos terão sua representação em todas as dimensões, além disso, dependendo a complexidade do signo de entrada e do trajeto que ele percorre até sua saída, pode ocorrer múltiplas sub-decisões que não é o objeto deste artigo descrever em seus enredamentos. 
Figura 1: Processo da semiose com base em Charles Morris.

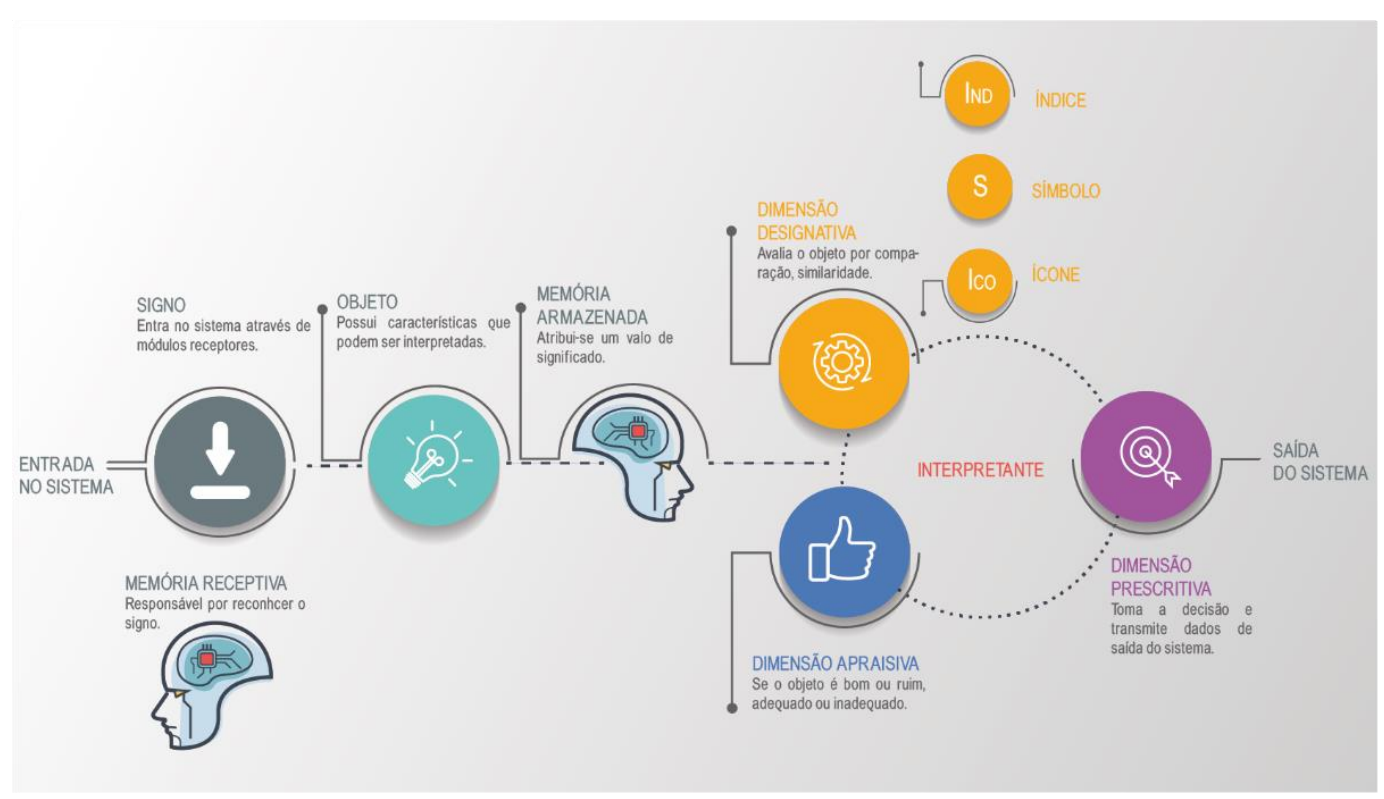

Fonte: elaborada pelos autores.

Na dimensão designativa, a qual atribui-se uma relação entre o signo e o objeto acontece a etapa de interpretação. Nela, o signo pode ser classificado em ícone, símbolo ou índice. Para acontecer o reconhecimento do ícone, que carrega um significado absoluto do signo interpretado, é necessário que o sistema tenha armazenado um repertório ou vocabulário desse signo. $\mathrm{O}$ signo que mais se parecer adequado a interpretação do sinal de entrada é designado então como intrepretante do signo. Este processo só ocorre em dados no qual a similaridade é significante.

Quando o significado está atrelado a uma convenção externa e não por similaridade, um símbolo foi atribuído ao signo. As ligações internas dos signos da memória do sistema se dão então por convenção e não por similaridade.

O índice é o mais complexo, pois não carrega em si o objeto que o denota, apenas faz referência ao mesmo. Nos sistemas artificiais ainda há pontos em aberto na modelagem desta forma de interpretação (GOMIDE; GUDWIN, 1996), por este motivo este artigo não pretende explorar mais a fundo esta abordagem.

\section{O VALOR DO PRODUTO DE MODA}

O Design como ação inovadora, se atem aos problemas dos usuários com o propósito de promover ações efetivas. Essas ações têm o objetivo de facilitar as experiências dos seres humanos na sua relação com o mundo. De maneira mais profunda, o design se ocupa da eficiência sociocultural na vida cotidiana. Esta ligação que Bonsiepe (1997) descreve, ilustra de forma clara que, além dos valores tangíveis dos produtos, os valores imateriais definem muito o tipo e a intensidade da relação entre o usuário e artefato. 
Um aplicativo de gerenciamento de estilos pode gerar diferentes sentidos e implicações para o usuário. Desde significados relacionados a auto imagem e identidade com contribuições psicológicas até conceitos associados ao consumo sustentável com melhor aproveitamento de um produto que tem uma vida material longa.

Não obstante, é importante ressaltar que o produto de moda tem duas características muito peculiares que é ser manufatureiro e cultural ao mesmo tempo. Cietta (2019) classifica-o como um produto híbrido por ter essas duas naturezas. Ou seja, ele é fortemente pautado em valores imateriais e predominantemente veículos de mensagens simbólicas, assim como também possui um forte aspecto material e funcional.

Sendo assim, o fator de decisão de compra ou uso de roupas pelo usuário são pautados tanto em elementos técnicos e de desempenho, como em diferentes causas não materiais. Esta subjetividade elencada na percepção do produto é representada pela imagem da marca que está relacionada a um complexo de ações como sustentabilidade ambiental, responsabilidade social e local de consumo.

Para determinar o valor de um produto Cietta (2019) afirma que a qualidade material pouco se relaciona com o preço, mas sim as variáveis percebidas e consideradas pelo consumidor como relevantes naquele momento.

Desta forma, o objetivo deste artigo é fazer uma reflexão se por meio da capacidade decisória de uma máquina é possível que ela desempenhe o papel de gerenciar estilos de roupas para usuários, assim como propõe o aplicativo "Save Your Wardrobe ${ }^{1 "}$ (SYW).

\section{MÁQUINAS PARA ESTILO}

Esta reflexão, se baseia nas proposições de soluções do aplicativo SYW e não na forma em que o software se estrutura ou foi configurado. Até mesmo, por estar em fases de testes, seria prématura uma análise de sua atuação.

A principal finalidade a que se propõe um aplicativo deste tipo é gerenciar as peças de vestuário do usuário por meio da criação de um guarda-roupa digital baseado nas roupas que o consumidor transfere para o sistema através de fotografias. O objetivo é que o sistema realize escolhas e combinações de peças para que o usuário vista em determinadas ocasiões. Como ponto central, está a capacidade da máquina avaliar de forma lógica todas as peças armazenadas, não esquecendo de nenhuma como acontece com os seres humanos, quando as roupas guardadas não estão na sua vista.

\footnotetext{
${ }^{1}$ https://www.saveyourwardrobe.com/
} 
Dentro deste conceito, se encaixam também aspectos relacionados a sustentabilidade, já que o aplicativo pode realizar essa manutenção do armário, no sentido de não deixar peças esquecidas ou sem uso, pois nesse caso, sugere que a roupa seja repassada para outras pessoas que tenham interesse em usá-la. O ponto central desta abordagem é criar relevância das roupas que o usuário tem em seu guarda-roupa.

Outros dados podem ser coletados pelo sistema por meio das redes sociais, criando diferentes categorias de valor, baseado em acessos, visualizações ou curtidas. Esses diferentes meios de receber informação são estímulos recebidos que, como nos seres humanos, passam por receptores e para possíveis interpretações devem ser considerado seus históricos (FREITAS, 2005).

Com base nas teorias semióticas, um aplicativo deste tipo pode reconhecer uma roupa por diferentes aspectos. Em primeiro, deve ter um módulo receptor que irá reconhecer as peças (signos) inseridas em seu acervo. Para cada uma, sua memória perceptiva recebe e reconhece os dados como peças do vestuário. Por meio da sua memória armazenada esses dados serão processados e na dimensão designativa, avaliados por similaridades e inseridos em diferentes categorias como, por exemplo por tipos: blusas, camisas, shorts, calças, casacos ou outros. O processo de avaliação desta decisão é baseado em certas características previamente inseridas que devem ser pautadas principalmente no formato da peça (modelagem), que conferem a ela essas propriedades. Por exemplo: um casaco é feito de dois módulos, com abertura frontal e em cada lado dessas partes possuem extensões que se referem as mangas para cobrir os braços. Quando a peça não segue esse parâmetro deve ser encaixada em outra categoria.

Na figura 2 é possível observar o processo decisório do reconhecimento de uma blusa de manga comprida. Em um primeiro momento o módulo receptivo recebe o sinal e reconhece o signo, pois na sua memória receptiva contém tais parâmetros. Na sequência o sistema reconhece então o signo como objeto e por meio da memória armazenada atua em diferentes dimensões. A demonstrada é a dimensão designativa que atua por processo de comparação. No nível do ícone a blusa pode ser avaliada em categorias como blusas, calças, casacos, saias, etc. E depois de tomada a decisão "blusa" é necessário avaliar outras subcategorias que irá depender da quantidade de variáveis inseridas no sistema. Como mostrado na figura alguns exemplos são: "blusas de manga comprida", "manga curta", "de alça" e assim segue. Quanto ao nível simbólico pode ser avaliada, por exemplo, a temperatura relacionada as condições de calor ou frio como restrição para a categorização deste objeto. E por convenção, mangas compridas ensejam que o ambiente esteja relativamente frio. Muitas outras avaliações podem e devem ser feitas até que haja uma avaliação consistente do signo de entrada. 
Figura 2: Exemplo de análise de uma blusa em um sistema semiótico.

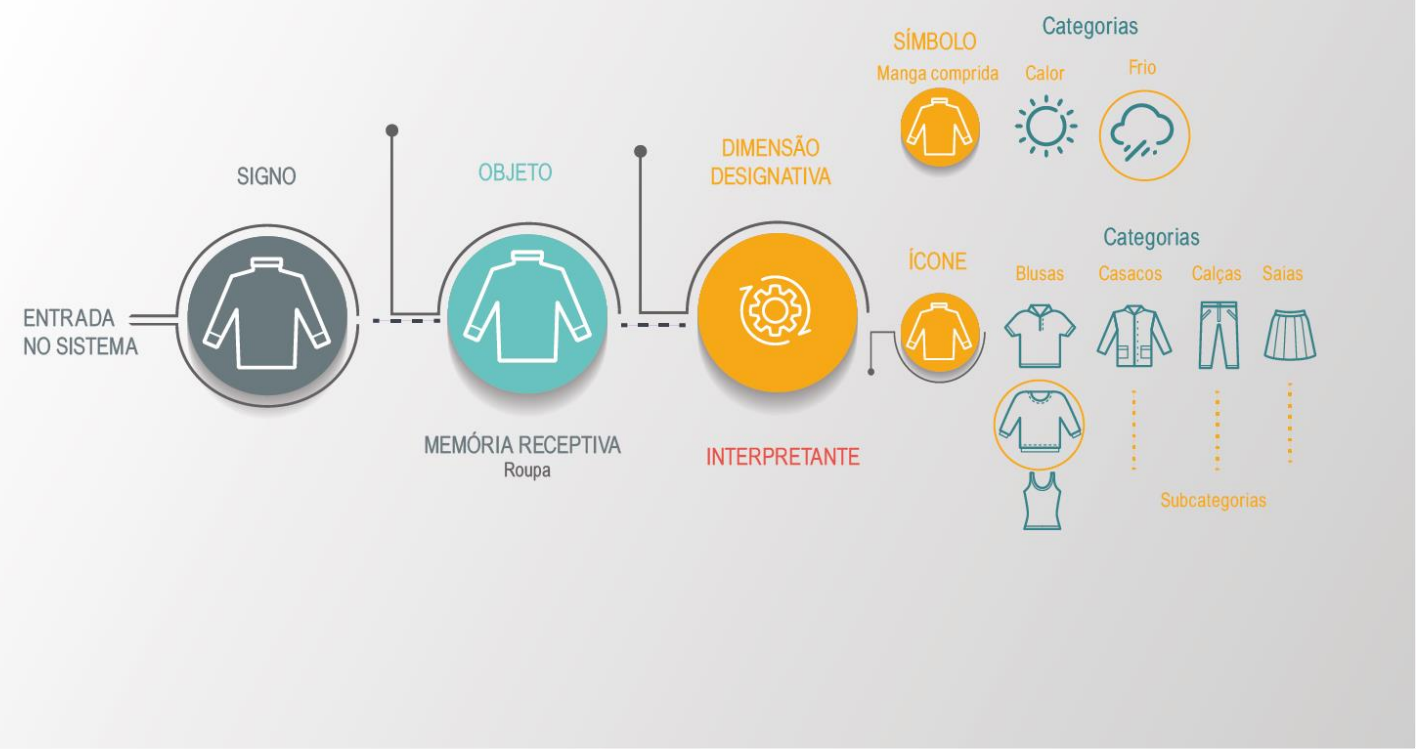

Fonte: elaborada pelos autores.

Na dimensão simbólica, as peças podem ser categorizadas em diferentes estilos. Isso é uma convenção social que é atribuída pelo meio externo. Desta forma, uma categoria anterior pode ser dividida em subcategorias, é o caso de uma blusa que consegue ser encaixada em diferentes estilos. Por exemplo: estilo casual, esportivo, festa, etc. Essas classes são baseadas em ocasiões de uso, pautadas em certos aspectos físicos do produto que designam este estilo. Por exemplo, uma blusa para festa deve conter certos elementos como brilho, renda, modelagens que apareçam mais o corpo, motivos de estampas específicos, entre muitos outros. O que leva o sistema a tomar essa decisão é baseado em aspectos inseridos anteriormente pelos agentes humanos, ou através de programações pelas quais o sistema poderá aprender através da captação de outros dados.

Considerando o cenário descrito da categorização de blusas em diferentes estilos, o sistema pode utilizar também dados coletados na internet como em redes sociais para tomar essa decisão. Para isso o sistema deve reconhecer e armazenar blusas que foram utilizadas em festas, por exemplo.

\section{CONSIDERAÇÕES FINAIS}

Os complexos processos realizados pelo sistema acontece para que ele possa tomar decisões para o usuário. Essas decisões compreendem também combinações de peças que podem ser configuradas tanto pela forma ou silhueta da roupa como por padrões e convenções externas. As convenções externas podem ser baseadas, por exemplo em misturar certos estilos e outros não. 
Então o sistema pode decidir misturar uma blusa esportiva com um estilo de calça casual para uma ocasião de uso como um passeio no parque. No entanto, não pode misturar uma calça noite com uma blusa esportiva para uma festa, por exemplo. Essas decisões todas dependem dos aspectos configurados anteriormente por um agente humano e de quais dados o sistema consegue captar, avaliar e armazenar em sua memória.

Para tomar decisões para o usuário então, o sistema deve ter acesso ao calendário do mesmo, avaliando quais ocasiões de uso por qual ele irá passar, compreender quais são as restrições simbólicas que compõe cada ocasião e ter categorizado as roupas por similaridade em subcategorias.

Além disso, outras restrições como a previsão do tempo também devem ser consideradas, já que a temperatura irá influenciar pelo uso de diferentes tecidos e modelagens. Para isso o sistema deve reconhecer as propriedades físicas e químicas dos têxteis, para classificar de forma adequada cada uma delas.

Entretanto, se fizermos uma reflexão mais profunda em relação aos aspectos de decisão de um usuário associado ao produto de moda, conforme citado por Cietta (2019), os valores imateriais são extremamente subjetivos e se dão pelos atributos reconhecidos não somente no produto, mas em todo o seu complexo produtivo. Formas de produção, por exemplo, como uso de elementos químicos no tingimento, acarreta prejuízos em relação aos recursos naturais como a água diminuindo, portanto, seu valor imaterial para determinados usuários. O uso de mão de obra em países onde as leis de responsabilidade social são falhas, dando margem ao trabalho escravo, também diminui seu valor imaterial. Por outro lado, produtos que desenvolvam socialmente uma categoria em risco, como certas comunidades (RECH; SOUZA, 2018), podem aumentar seu valor imaterial.

Neste caso, percebe-se que se tratarmos a decisão das máquinas por aspectos mais facilmente reconhecíveis, um aplicativo de gerenciamento de roupas é uma máquina que aprende, seleciona opções entre várias alternativas e pode melhorar a qualidade de vida dos usuários em determinadas condições.

Por outro lado, ao tratar este usuário em sua complexidade de decisões na atribuição de valor a um produto, questiona-se se os sistemas teriam a possibilidade de reconhecer esses padrões para diferentes pessoas. Neste caso, considerando estilos de vida, crenças, cultura do usuário e adicionando as variáveis materiais do produto, a quantidade de escolhas tende ao infinito, tornando praticamente inviável que uma máquina consiga tomar decisões que considerem todas essas circunstâncias de forma parecida com a humana. 


\section{REFERÊNCIAS}

BONSIEPE, G. DESIGN: do material ao digital. Florianópolis: FIESC/IEL, 1997.

CIETTA, E. A Economia da moda. São Paulo: Estação das Letras e Cores, 2019.

FACELI, K. et al. Inteligência Artificial: uma abordagem de aprendizado de máquina. Rio de Janeiro: LTC, 2011.

FREITAS, J. C. de. O design como interface de comunicação e uso em linguagens hipermidiáticas. In: LEÃO, L. (org.). 0 chip e o caleidoscópio: reflexões sobre as novas mídias. São Paulo: Senac, 2005. p. 183-196.

GOMIDE, R. R.; GUDWIN, F. A. C. Sistemas Inteligentes Semióticos segundo a Semiótica Behaviorista de Charles Morris. Campinas: UNICAMP, 1996.

MORRIS, C. Fundamentos da Teoria dos Signos. Covilhã : Universidade da Beira Interior, 1994.

NORMAN, D. O Design do Futuro. Rio de Janeiro: Rocco, 2010.

NÖTH, W. Máquinas semióticas. Galáxia, São Paulo, n.1, 2001. Disponível em: https://revistas.pucsp.br/index.php/galaxia/article/view/1057. Acesso em: 05 dez. 2019.

RECH, S. R.; SOUZA, R. K. R. de. Ecoluxo e sustentabilidade: um novo comportamento do consumidor. DAPesquisa, Florianopolis, v. 4, n. 6, p. 602-608, 2018. Disponível em: https://revistas.udesc.br/index.php/dapesquisa/article/view/14232. Acesso em: 05 dez. 2019

SOUSA, R. P. L. de. Mídia do conhecimento: ideias sobre mediação e autonomia. Florianópolis : SIGMO/UFSC, 2019.

VIANNA, M. et al. Inteligência Artificial: como ela está transformando os modelos de negócios. Rio de Janeiro: MJV Press, 2019. 